\title{
Openness to Experience
}

\author{
Alexander P. Christensen, alexpaulchristensen@gmail.com \\ University of North Carolina at Greensboro \\ Greensboro, North Carolina, United States of America
}

This chapter has been submitted to The Palgrave Encyclopedia of the Possible. This is a pre-review draft, which may not reflect the final typeset version. The final version will be made available from SpringerLink: https://link.springer.com/referencework/10.1007/978-3-319-98390-5

\section{Definition}

As one of the five major personality traits, openness to experience has been established as a fundamental factor of personality. Yet its history, and what it constitutes, has not always been clear. This becomes obvious when observing how the label has changed over the decades: from Inquiring Intellect to Intelligence to Culture until finally the consensus of Openness to Experience. This final connotation denotes people who are flexible and receptive to all experiential possibilities. It is this flexibility that perhaps most defines open people and enables them to be creative, establish complex worldviews, and probe the depths of human experience. Therefore, open people not only see more possibilities but also engage with them. This chapter starts with a brief review of the history of openness to experience that leads into contemporary conceptualizations. It then moves on to discussing research on the trait's associations with cognitive, perceptual, and behavioral outcomes. Finally, specific emphasis is placed on types of experience and how these may vary depending on people's characteristics of openness to experience.

Keywords: openness to experience, creativity, cognition, perception, curiosity

\section{Definition and history}

Openness to experience is a broad and complex trait whose definition has been contentiously debated over the years. The origins of openness to experience can be traced back to Cattell 
(1947), who used an intelligence test and natural language descriptor ratings to derive primary factors of personality. Of these factors, he found three that resemble contemporary aspects of openness to experience: Intelligence, Imaginative Emotionality, and Bohemian Intellectualism. Performing a similar study, Fiske (1949) identified five recurring factors with the fourth factor being labelled, "Inquiring Intellect," denoting characteristics that emphasized intellectual curiosity (see section Curiosity). Later factor analytic studies found that these intellectual characteristics tended to associate with more "culturally refined" qualities such as autonomy and appreciation for aesthetics, leading to a label of "Culture" (Norman, 1963; Tupes \& Christal, 1961/1992).

Since these seminal studies, the conceptualization of openness to experience has continued to expand with studies examining English language adjectives (Goldberg, 1981) and behavioral correlates such as hypnotic susceptibility (Tellegen \& Atkinson, 1974). The culmination of these works formed a consensus label of "Openness to Experience" (Costa \& McCrae, 1976; Rogers, 1954). Costa and McCrae (1978) led this consensus by elaborating on the trait's structural definitions and establishing a broader agreement on the trait's conceptualization (McCrae \& Costa, 1997). Encompassing this broader definition, open people were described as having "[flexible] boundaries in concepts, beliefs, perceptions, and hypotheses" (Rogers, 1954, p. 254) and by "[their] breadth, depth, and permeability of consciousness [(see section Consciousness)], and [their] recurrent need to enlarge and examine experience" (McCrae \& Costa, 1997, p. 826).

More recent perspectives are centered around these definitions, which is reflected in contemporary self-report inventories. McCrae and Costa's own inventory, the NEO-PI-3 (McCrae, Costa, \& Martin, 2005), was designed to capture the breadth of the trait using six lower-order facets: actions (openness to new experiences on a practical level), aesthetics (appreciation of art and nature; see section Aesthetics), fantasy (receptivity to the inner world of imagination; see section Imagination), feelings (openness to inner feelings and emotions; see section Emotion), ideas (intellectual curiosity), and values (readiness to reexamine one's own values and those of authority figures). Another notable inventory is DeYoung, Quilty, and Peterson's (2007) Big Five Aspects Scale, which breaks openness to experience into two aspects: Openness and Intellect. The Openness aspect (hereafter referred to as Experiencing; Connelly, Ones, Davies, \& Birkland, 2014) denotes engagement with aesthetic and perceptual experiences, 
while the Intellect aspect denotes engagement with semantic and intellectual information. These aspects represent higher-order summaries of the NEO-PI-3's facets, reflecting separate but related dimensions of openness to experience.

Although a broader consensus has been established in the conceptualization and assessment of openness to experience, there still remains some debate about the taxonomy of the trait - that is, the number and type of characteristics that make up the trait. Connelly and colleagues (2014) examined this issue using a top-down theoretical sort and meta-analytic approach to identify "core" components of openness to experience that were solely related to openness to experience and "compound" components that were related to openness to experience and other traits. In their study, they identified eleven components: four core (aestheticism, openness to sensations, nontraditionalism, and introspection) and seven compound (openness to emotions, innovation, variety-seeking, fantasy, tolerance, autonomy, and thrill-seeking).

Similarly, Christensen, Cotter, and Silvia (2019) examined this issue using a bottom-up network analytic approach to identify components from four different openness to experience inventories. They found ten components (aesthetic appreciation, diversity, fantasy, imaginative, intellectual curiosity, intellectual interests, nontraditionalism, openness to emotions, selfassessed intelligence, and variety-seeking), which largely corresponded with Connelly and colleagues' findings. When taken together, these studies provide a fruitful framework for developing new measures of openness to experience that comprehensively represent its contemporary taxonomy.

\section{Outcomes related to openness to experience}

The breadth of characteristics encompassed by openness to experience are associated with nearly every faculty of human psychology - from cognition and memory to perception and emotion to behavioral and psychopathological functioning. Before discussing some of these outcomes, it's important to make clear who openness to experience refers to. Although it's common to say that individual people possess openness to experience, it's more appropriate to say that openness to experience is a common dimension of personality that represents "a category for classifying functionally equivalent forms of behavior in a general population of people" (Allport, 1961, p. 340). Therefore, when referring to open people, this reference is for a population of people that are higher on characteristics of openness to experience relative to other populations rather than an individual person. 
The most researched outcomes of openness to experience are related to cognition. More than any other trait, openness to experience is defined by cognitive characteristics (Zillig, Hemenover, \& Dienstbier, 2002). This is perhaps not surprising given the trait's early links to intelligence, including intelligence being considered a part of the trait (Cattel, 1947). Beyond intelligence, open people's most notable attribute is their tendency to be creative (Oleynick et al., 2017). This association is found in nearly every measure of creativity: divergent thinking (Silvia et al., 2008; see section Divergent Thinking), creative self-efficacy (Karwowski \& Lebuda, 2016; see section Creative Mindsets), creative hobbies (Conner \& Silvia, 2015), and creative achievements (Kaufman et al., 2016).

One common cognitive thread underlying both creativity and openness to experience is their neural architecture. Both phenomena have been shown to be associated with the functional connectivity between cognitive control (lateral prefrontal and anterior inferior parietal regions) and default mode networks (a set of cortical midline, medial temporal, and posterior inferior parietal regions; Beaty et al., 2015, 2018). These networks are thought to support executive and associative memory processes, respectively. Further evidence of this cognitive linkage has been demonstrated in studies examining the associative structure of memory. Both creative and open people are shown to have more interconnected and flexible associations between concepts in their semantic memory, which may allow them to be more cognitively flexible (Christensen, Kenett, Cotter, Beaty, \& Silvia, 2018; Kenett, Anaki, \& Faust, 2014). Therefore, open people may think and reason about the world differently than less open people.

Open people may not only think about the world differently but also perceive the world differently. There is growing evidence that open people have different reactions to sensory and perceptual stimulus. Early work in this area has focused on aesthetic chills or the experience of goose bumps and shivers in response to the arts, which has been denoted as "a universal marker of openness to experience" (McCrae, 2007). Open people seem to experience aesthetic chills more often in response to art (Nusbaum \& Silvia, 2011) and music (Silvia \& Nusbaum, 2011) than less open people. Awe (see section Awe) is another experience open people often have in response to aesthetic appreciation (e.g., nature and music; Silvia, Fayn, Nusbaum, \& Beaty, 2015), including being more likely to feel like crying during music that produces awe experiences (Cotter, Silvia, \& Fayn, 2018). This seems to suggest that open people experience a broader range of emotions. This is supported by research demonstrating that open people 
experience mixed emotional states (i.e., concurrent feelings of positive and negative affect) more often than less open people (Barford \& Smillie, 2016).

These mixed emotional states sometimes occur with appraisals of visual art, indicating that there's a connection between cognitive and perceptual processes (Barford, Fayn, Silvia, \& Smillie, 2018). More recent work has demonstrated that open people's perceptual processing may differ at low levels, suggesting these emotional states may start from the bottom-up (Antinori, Carter, \& Smillie, 2017). Antinori and colleagues (2017) examined the phenomenon of binocular rivalry — when visual perception alternates between stimuli and neither stimuli are fully suppressed - in relation to personality. They found that open people reported experiencing more binocular rivalry, meaning that open people were more prone to combining perceptual information at a basic level.

This finding is consistent with evidence indicating that open people tend to have a "leakier" filter for preconscious information, which is often referred to as latent inhibition (Peterson, Smith, \& Carson, 2002). Open people are shown to have decreased latent inhibition, meaning they are less likely to ignore stimuli previously experienced as irrelevant, thereby increasing the range of associations for stimuli. These overinclusive associations may come at a cost: seeing meaningful patterns and associations when there are none. This phenomenon is known as apophenia and is a prominent feature of psychosis, particularly with positive symptoms of schizophrenia-spectrum disorders (i.e., symptoms that are present that are usually not). Given this connection between openness to experience and overinclusive associations, it's not surprising that there is a positive association between openness to experience and positive schizotypy (sub-clinical to clinical traits of positive schizophrenia-spectrum symptoms; Kemp, Burgin, Raulin, \& Kwapil, in press).

In DeYoung, Grazioplene, and Peterson's (2012) Openness/Intellect simplex model, apophenia is at the extreme end of the Openness (Experiencing) aspect. More recent research has expanded on this view, positing a unified framework that places the Experiencing aspect on the same continuum with psychoticism and apophenia (from typical personality variation to psychopathology; Blain, Longenecker, Grazioplene, Klimes-Dougan, \& DeYoung, in press). This framework is supported by neurological evidence demonstrating that the shared variance between Experiencing and Psychoticism is linked to increased network coherence in the default mode network and decreased coherence in the cognitive control network (Blain, Grazioplene, 
Ma, \& DeYoung, in press). This suggests that those who are on the extreme end of the Experiencing continuum may be more psychosis prone.

\section{Possibility and types of experience}

In this brief review on the outcomes of openness to experience, it should hopefully be clear that open people's experiences represent a spectrum of cognitive, perceptual, and behavioral possibilities. It's necessary to reiterate that these findings likely do not apply to every individual high on openness to experience but is more representative of the population of highly open people. For individual people, the trait may manifest as types of openness to experience rather than the breadth of the trait.

Take the example of a classic openness to experience archetype: The artist. Kaufman and colleagues (2016) found that high achieving people in the arts domain tended to be higher on the Experiencing aspect of openness to experience than the Intellect aspect. Certainly, some artists may be more intellectual than others but what characterizes most artists is that they engage with aesthetic and perceptual experiences (DeYoung et al., 2012; see section Possible in Performance and Performing Arts, Possible in Visual Arts, and The Possible in Music). Similarly, they found that high achieving people in the sciences domain tended to be higher on the Intellect aspect of openness to experience than the Experiencing. Once again, some scientists may be more aesthetically inclined than others but they are most notably characterized by their engagement with intellectual experiences (DeYoung et al., 2012).

One type of experience that is scarcely measured in contemporary openness to experience inventories is an openness to socio-cultural experiences (but see Woo et al., 2014). In Christensen and colleagues' (2019) openness to experience network, they found evidence of an Open-Mindedness aspect, which was defined as "a receptiveness toward others' ideas, values, beliefs, lifestyles, and culture" (p. 10). There is good reason to suspect that this is an important part of openness to experience types as these people may be more open to cross-cultural experiences such as trying new foods or engaging in local traditions (McCrae et al., 2005; Woo et al., 2014). There is some evidence to suggest that having cross-cultural experiences, such as studying abroad in college, may increase people's openness to experience (Martin, KatzBuonincontro, \& Livert, 2015).

These examples indicate that the types of experiences that people are open to facilitate different types of possibilities. Being open to other cultures, for example, may facilitate 
perspective-taking (see section Perspective-taking) and empathy (see section Empathy) for those living in different parts of the world. Without that openness, a person could remain closed-off to considering others' circumstances and their worldview may not change. A sense of humour (see section Humour) is another example: What is a sense of humour without the openness to entertain conflicting worldviews or maintain incompatible social and semantic scripts (Attardo, 1994)? Thus, a tendency to be open to an experience is a prerequisite for exploring its possibilities.

Across different types of experience, there are likely common motivational factors, such as curiosity, that contribute to seeking out new possibilities (Kashdan et al., 2018). Indeed, a drive to explore the unknown is fundamental to openness to experience (DeYoung, 2013). One person might seek out complex and abstract artwork because it provides an opportunity for personal growth, while another person might be driven towards scientific discovery because they want to know the unknown (Kashdan et al., 2018). When it comes to exploring types of experience, specific characteristics of the trait (e.g., NEO-PI-3 facets) may better explain who is driven towards what (Mõttus, 2016). Therefore, future research on openness to experience should consider what components of the trait are contributing to the types of experiences and outcomes under study.

\section{Summary}

Openness to experience is a complex trait that represents the breadth of human experience. Its definition has become better realized over the years with contemporary models arriving at a clearer consensus. From this consensus, it's apparent that openness to experience captures an openness for all types of human experience: cognitive, perceptual, behavioral, and even sociocultural. Open people not only see the world differently but engage with it differently. Importantly, not all open people are alike, each having their specific drives and motivations for distinct types of experience. Through these different types of experience, open people engage with the unknown and explore the edges of the possible.

\section{Cross-references}

Aesthetics

Awe

Consciousness

Creative Mindsets 
Curiosity

Divergent Thinking

Emotions

Empathy

Humour

Imagination

Perspective-taking

Possible in Performance and Performing Arts

Possible in Visual Arts

The Possible in Music

\section{References}

Allport, G. W. (1961). Pattern and growth in personality. New York, NY: Holt, Reinhart \& Winston.

Antinori, A., Carter, O. L., \& Smillie, L. D. (2017). Seeing it both ways: Openness to experience and binocular rivalry suppression. Journal of Research in Personality, 68, 15-22. https://doi.org/10.1016/j.jrp.2017.03.005

Attardo, S. (1994). Linguistic theories of humor. Berlin: Mouton de Gruyter.

Barford, K. A., Fayn, K., Silvia, P. J., \& Smillie, L. D. (2018). Individual differences in conflicting stimulus evaluations: Openness/Intellect predicts mixed-valenced appraisals of visual art. Journal of Research in Personality, 73, 46-55. https://doi.org/10.1016/j.jrp.2017.11.006

Barford, K. A., \& Smillie, L. D. (2016). Openness and other Big Five traits in relation to dispositional mixed emotions. Personality and Individual Differences, 102, 118-122. https://doi.org/10.1016/j.paid.2016.07.002

Beaty, R. E., Benedek, M., Kaufman, S. B., \& Silvia, P. J. (2015). Default and executive network coupling supports creative idea production. Scientific Reports, 5, 10964. https://doi.org/10.1038/srep10964

Beaty, R. E., Chen, Q., Christensen, A. P., Qiu, J., Silvia, P. J., \& Schacter, D. L. (2018). Brain networks of the imaginative mind: Dynamic functional connectivity of default and cognitive control networks relates to openness to experience. Human Brain Mapping, 39, 811-821. https://doi.org/10.1002/hbm.23884 
Blain, S. D., Grazioplene, R. G., Ma, Y., \& DeYoung, C. G. (in press). Toward a neural model of the Openness-Psychoticism dimension: Functional connectivity in the default and frontoparietal control networks. Schizophrenia Bulletin. https://doi.org/10.1093/schbul/sbz103

Blain, S. D., Longenecker, J. M., Grazioplene, R. G., Klimes-Dougan, B., \& DeYoung, C. G. (in press). Apophenia as the disposition to false positives: A unifying framework for the Openness-Psychoticism dimension. Journal of Abnormal Psychology. https://doi.org/10.31234/osf.io/d9wkc

Cattell, R. B. (1947). Confirmation and clarification of primary personality factors. Psychometrika, 12, 197-220. https://doi.org/10.1007/BF02289253

Christensen, A. P., Cotter, K. N., \& Silvia, P. J. (2019). Reopening openness to experience: A network analysis of four openness to experience inventories. Journal of Personality Assessment, 101, 574-588. https://doi.org/10.1080/00223891.2018.1467428

Christensen, A. P., Kenett, Y. N., Cotter, K. N., Beaty, R. E., \& Silvia, P. J. (2018). Remotely close associations: Openness to experience and semantic memory structure. European Journal of Personality, 32, 480-492. https://doi.org/10.1002/per.2157

Connelly, B. S., Ones, D. S., Davies, S. E., \& Birkland, A. (2014). Opening up openness: A theoretical sort following critical incidents methodology and a meta-analytic investigation of the trait family measures. Journal of Personality Assessment, 96, 17-28. https://doi.org/10.1080/00223891.2013.809355

Conner, T. S., \& Silvia, P. J. (2015). Creative days: A daily diary study of emotion, personality, and everyday creativity. Psychology of Aesthetics, Creativity, and the Arts, 9, 463-470. https://doi.org/10.1037/aca0000022

Costa, P. T., \& McCrae, R. R. (1976). Age differences in personality structure: A cluster analytic approach. Journal of Gerontology, 31, 564-570. https://doi.org/10.1093/geronj/31.5.564

Costa, P. T., \& McCrae, R. R. (1978). Objective personality assessment. In M. Storandt, I. C. Siegler, \& M. F. Elias (Eds.), The clinical psychology of aging (pp. 119-143). New York, NY: Plenum Press.

Cotter, K. N., Silvia, P. J., \& Fayn, K. (2018). What does feeling like crying when listening to music feel like? Psychology of Aesthetics, Creativity, and the Arts, 12, 216-227. https://doi.org/10.1037/aca0000108 
DeYoung, C. G. (2013). The neuromodulator of exploration: A unifying theory of the role of dopamine in personality. Frontiers in Human Neuroscience, 7, 762. https://doi.org/10.3389/fnhum.2013.00762

DeYoung, C. G., Grazioplene, R. G., \& Peterson, J. B. (2012). From madness to genius: The Openness/Intellect trait domain as a paradoxical simplex. Journal of Research in Personality, 46, 63-78. https://doi.org/10.1016/j.jrp.2011.12.003

DeYoung, C. G., Quilty, L. C., \& Peterson, J. B. (2007). Between facets and domains: 10 aspects of the Big Five. Journal of Personality and Social Psychology, 93, 880-896. https://doi.org/10.1037/0022-3514.93.5.880

Goldberg, L. R. (1981). Language and individual differences: The search for universals in personality lexicons. In L. Wheeler (Ed.), Review of personality and social psychology (Vol. 2, pp. 141-165). Beverly Hills, CA: Sage.

Karwowski, M., \& Lebuda, I. (2016). The big five, the huge two, and creative self-beliefs: A meta-analysis. Psychology of Aesthetics, Creativity, and the Arts, 10, 214-232. https://doi.org/10.1037/aca0000035

Kashdan, T. B., Stiksma, M. C., Disabato, D. J., McKnight, P. E., Bekier, J., Kaji, J., \& Lazarus, R. (2018). The five-dimensional curiosity scale: Capturing the bandwidth of curiosity and identifying four unique subgroups of curious people. Journal of Research in Personality, 73, 130-149. https://doi.org/10.1016/j.jrp.2017.11.011

Kaufman, S. B., Quilty, L. C., Grazioplene, R. G., Hirsh, J. B., Gray, J. R., Peterson, J. B., \& DeYoung, C. G. (2016). Openness to experience and intellect differentially predict creative achievement in the arts and sciences. Journal of Personality, 84, 248-258. https://doi.org/10.1111/jopy.12156

Kemp, K. C., Burgin, C. J., Raulin, M. L., \& Kwapil, T. R. (in press). Using multiple measures of openness to experience to capture positive, negative, and disorganized dimensions of schizotypy. Personality Disorders: Theory, Research, and Treatment. https://doi.org/10.1037/per0000389

Kenett, Y. N., Anaki, D., \& Faust, M. (2014). Investigating the structure of semantic networks in low and high creative persons. Frontiers in Human Neuroscience, 8, 407. https://doi.org/10.3389/fnhum.2014.00407

Oleynick, V. C., DeYoung, C. G., Hyde, E., Kaufman, S. B., Beaty, R. E., \& Silvia, P. J. (2017). 
Openness/Intellect: The core of the creative personality. In G. J. Feist, R. Reiter-Palmon, \& J. C. Kaufman (Eds.), The Cambridge handbook of creativity and personality research (pp. 9-27). Cambridge, UK: Cambridge University Press. https://doi.org/10.1017/9781316228036.002

Martin, D., Katz-Buonincontro, J., \& Livert, D. (2015). Understanding the role of openness to experience in study abroad students. Journal of College Student Development, 56, 619625. https://doi.org/10.1353/csd.2015.0067

McCrae, R. R. (2007). Aesthetic chills as a universal marker of openness to experience. Motivation and Emotion, 31, 5-11. https://doi.org/10.1007/s11031-007-9053-1

McCrae, R. R., \& Costa, P. T. (1997). Conceptions and correlates of openness to experience. In R. Hogan, J. Johnson, \& S. Briggs (Eds.), Handbook of personality psychology (pp. 825847). San Diego, CA: Academic Press.

McCrae, R. R., Costa, P. T., \& Martin, T. A. (2005). The NEO-PI-3: A more readable revised NEO personality inventory. Journal of Personality Assessment, 84, 261-270. https://doi.org/10.1207/s15327752jpa8403_05

Mõttus, R. (2016). Towards more rigorous personality trait-outcome research. European Journal of Personality, 30, 292-303. https://doi.org/10.1002/per.2041

Norman, W. T. (1963). Toward an adequate taxonomy of personality attributes: Replicated factor structure in peer nomination personality ratings. Journal of Abnormal and Social Psychology, 66, 574-583. https://doi.org/10.1037/h0040291

Nusbaum, E. C., \& Silvia, P. J. (2011). Shivers and timbres: Personality and the experience of chills from music. Social Psychological and Personality Science, 2, 199-204. https://doi.org/10.1177/1948550610386810

Peterson, J. B., Smith, K. W., \& Carson, S. (2002). Openness and extraversion are associated with reduced latent inhibition: Replication and commentary. Personality and Individual Differences, 33, 1137-1147. https://doi.org/10.1016/S0191-8869(02)00004-1

Rogers, C. R. (1954). Toward a theory of creativity. ETC: A Review of General Semantics, 249260.

Silvia, P. J., Fayn, K., Nusbaum, E. C., \& Beaty, R. E. (2015). Openness to experience and awe in response to nature and music: Personality and profound aesthetic experiences. Psychology of Aesthetics, Creativity, and the Arts, 9, 376-384. 


\section{https://doi.org/10.1037/aca0000028}

Silvia, P. J., \& Nusbaum, E. C. (2011). On personality and piloerection: Individual differences in aesthetic chills and other unusual aesthetic experiences. Psychology of Aesthetics, Creativity, and the Arts, 5, 208-214. https://doi.org/10.1037/a0021914

Silvia, P. J., Winterstein, B. P., Willse, J. T., Barona, C. M., Cram, J. T., Hess, K. I., Martinez, J. L., \& Richard, C. A. (2008). Assessing creativity with divergent thinking tasks: Exploring the reliability and validity of new subjective scoring methods. Psychology of Aesthetics, Creativity, and the Arts, 2, 68-85. https://doi.org/10.1037/1931-3896.2.2.68

Tellegen, A., \& Atkinson, G. (1974). Openness to absorbing and self-altering experiences (“absorption"), a trait related to hypnotic susceptibility. Journal of Abnormal Psychology, 83, 268-277. https://doi.org/10.1037/h0036681

Tupes, E. C., \& Christal, R. E. (1961/1992). Recurrent personality factors based on trait ratings. Journal of Personality, 60, 225-251. https://doi.org/10.1111/j.1467-6494.1992.tb00973.x

Woo, S. E., Chernyshenko, O. S., Longley, A., Zhang, Z. X., Chiu, C. Y., \& Stark, S. E. (2014). Openness to experience: Its lower level structure, measurement, and cross-cultural equivalence. Journal of Personality Assessment, 96, 29-45. https://doi.org/10.1080/00223891.2013.806328

Zillig, L. M. P., Hemenover, S. H., \& Dienstbier, R. A. (2002). What do we assess when we assess a Big 5 trait? A content analysis of the affective, behavioral, and cognitive processes represented in Big 5 personality inventories. Personality and Social Psychology Bulletin, 28, 847-858. https://doi.org/10.1177/0146167202289013 